\title{
Semiconductor Ring Lasers Fabricated with UV Laser-assisted Cryo-etching
}

\author{
Chia-Ho Tsai, Chun-Hao Lee, Hsin-Jiun Chiang and C. C. Yang \\ Institute of Electro-Optical Engineering and Department of Electrical Engineering \\ National Taiwan University, 1, Roosevelt Road, Sec. 4, Taipei, Taiwan, R.O.C. \\ phone: 886-2-3635251 ext. 445 fax: 886-2-3652637 E-mail: ccy@cc.ee.ntu.edu.tw
}

M. C. Shih

Electronics Research \& Service Organization, ITRI, Hsin Chu, Taiwan, R.O.C.

B. C. Chen

Department of Chemistry, National Taiwan University, Taipei, Taiwan, R.O.C.

T. J. Chuang

Institute of Atomic and Molecular Sciences, Academia Sinica, Taipei, Taiwan, R.O.C.

Semiconductor circular ring lasers have attracted quite much attention because of the higher side-mode suppression ratio and the versatility of integration with other components. In order to reduce the scattering loss in the curved waveguide of such a ring laser, the etched wall of the waveguide ridge must be highly vertical and smooth. In the past, RIE dry etching was the major technique used for this etching process [1]. In this paper, we present the results of our GaAs/AlGaAs quantum well circular ring lasers which were etched with the UV laser-assisted cryo-etching technique

In the cryo-etching technique [2], we first placed the sample inside a chamber of about $130 \mathrm{~K}$, which was filled with $\mathrm{Cl}_{2}$. The $\mathrm{Cl}_{2}$ molecules would be physisorbed on the sample surface. Then, the UV photons from $193 \mathrm{~nm}$ excimer laser would dissociate physisorbed $\mathrm{Cl}_{2}$ and desorb Chlorine compounds (e.g., $\mathrm{GaCl}_{3}$ ). In such a process, the sample can be etched. Because of the directional illumination of excimer laser, it is expected that the etched wall is vertical and smooth. In etching our laser epitaxial structure, the $\mathrm{Cl}_{2}$ pressure was $1 \mathrm{~m}$ Torr and the $193 \mathrm{~nm}$ laser energy density was $13 \mathrm{~mJ} / \mathrm{cm}^{2}$ ( $5 \mathrm{~Hz}$ pulse repetition rate and $15 \mathrm{nsec}$ pulse width). With laser illumination for 10 minutes, we could achieve etching depth around $1 \mu \mathrm{m}$, by which the curved ridge-loading or ridge waveguide was formed.

The ring cavity structure is in a $\sigma$-configuration as shown in Fig. 1. The epitaxial structure includes a 5-period GaAs/AlGaAs quantum well layer and an about $1.5 \mu \mathrm{m}$ upper cladding layer. The ridge-loading or ridge waveguide has the ridge width $6 \mu \mathrm{m}$ and ring radius varied from 100 to $300 \mu \mathrm{m}$. The orientation of the output arm was also varied from 0 to $15^{\circ}$ with respect to the crystal cleaved facet. Figure 2 shows the L - I curve of a typical laser with the radius $300 \mu \mathrm{m}$ and $15^{\circ}$ tilt angle. The cryo-etching depth was $2 \mu \mathrm{m}$ meaning that a ridge waveguide was formed. It can be seen that the threshold current is about $120 \mathrm{~mA}$, corresponding to a threshold current density $839 \mathrm{~A} / \mathrm{cm}^{2}$. In the range of the injection current between 130 and $160 \mathrm{~mA}$, the laser efficiency was estimated to be $8.32 \%$, which is much higher than those of the similar ring lasers processed with the same cryo-etching technique (less than $2 \%$ ) [3] and those etched with RIE (less than $4 \%$ ) [1]. Figure 3 shows a typical spectrum just below the threshold condition. We can see the clear Fabry-Perot pattern which shows the free spectral range a little bit larger than 1 $\mathrm{nm}$. This value is about ten times that of the ring cavity itself. We suppose that the coupledcavity effect between the ring and the output arm may be responsible for this difference. Finally, 
Fig. 4 shows a typical spectrum above threshold. During the measurements, we could observe mode-hopping. We are currently conducting theoretical studies for explaining these phenomena.

\section{References:}

1. J. P. Hohimer, G. R. Hadley and G. A. Vawter, Appl. Phys. Lett. 63, 278, 1993.

2. M. C. Shih, M. B. Freiler, R. Scarmozzino and R. M. Osgood, Jr., J. Vac. Sci. Technol. B13, 43, 1995.

3. M. C. Shih, M. H. Hu, M. B. Freiler, M. Levy, R. Scarmozzino, R. M. Osgood, Jr., I. W. Tao and W. I. Wang, Appl. Phys. Lett. 66, 2608, 1995.

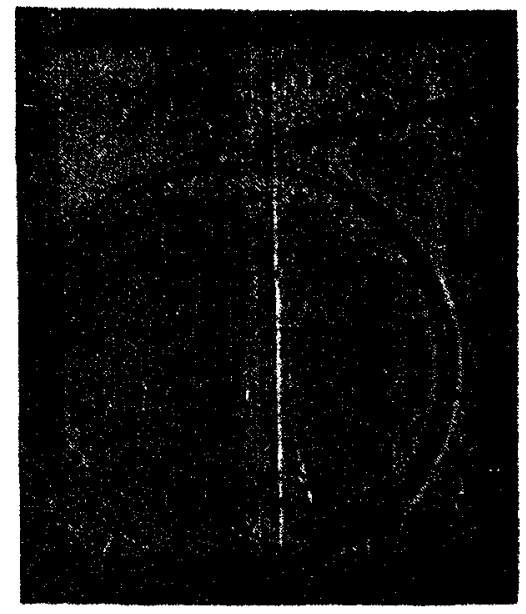

Fig. 1 Top view of a ring laser

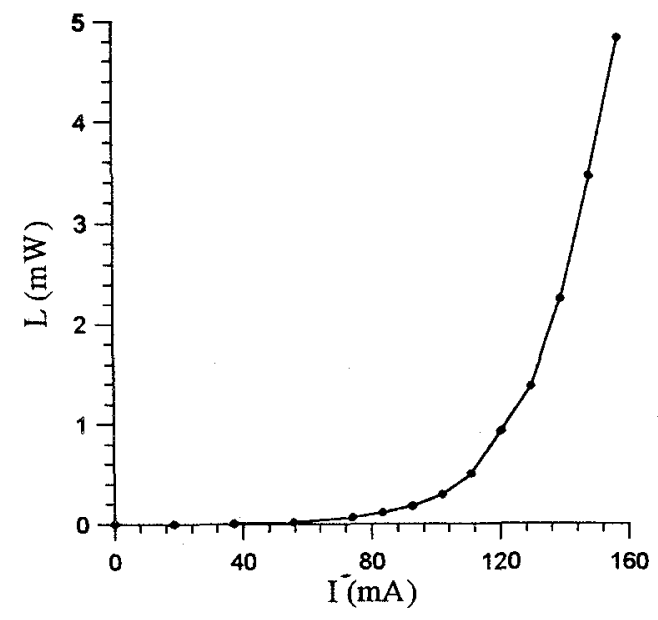

Fig. $2 \mathrm{~L}-\mathrm{I}$ curve of a typical ring laser.

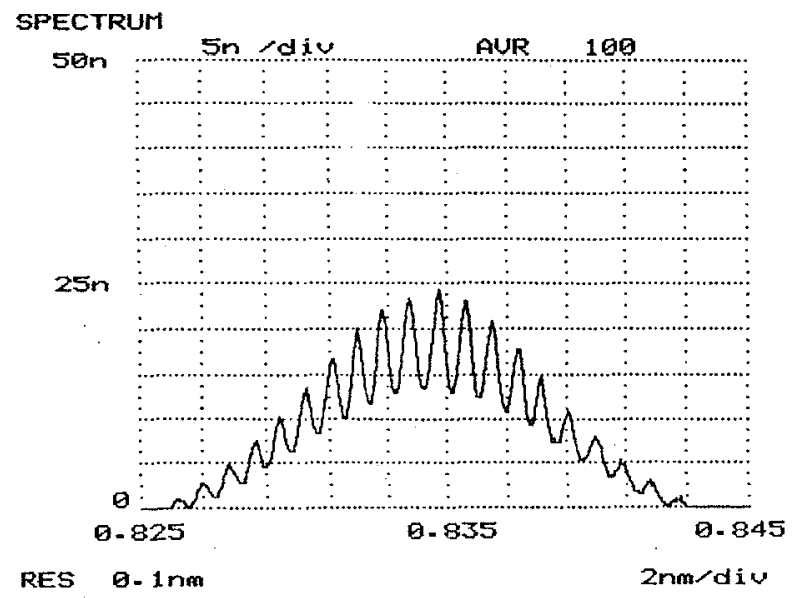

Fig. 3 A typical spectrum below threshold.

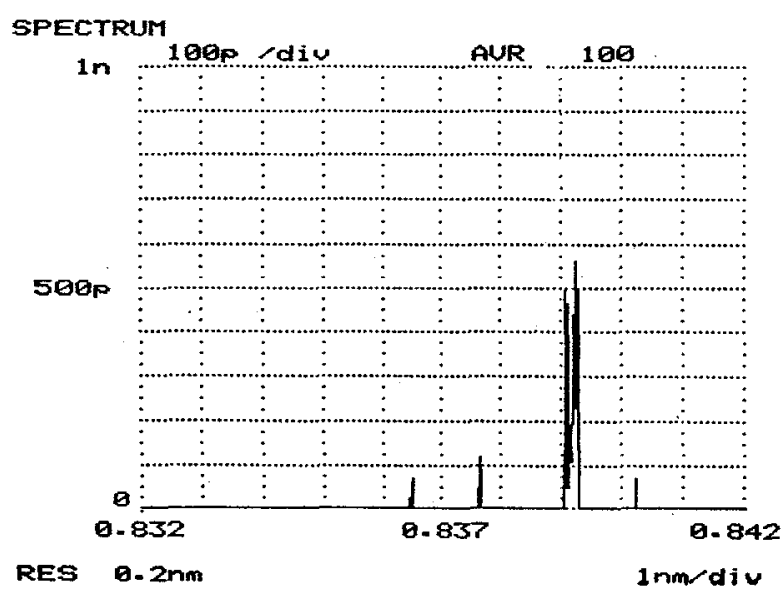

Fig. 4 A typical spectrum above threshold. 